\title{
Early treatment of Class III malocclusion: 10-year clinical follow-up
}

\author{
Marcio Rodrigues de ALMEIDA¹, Renato Rodrigues de ALMEIDA², Paula Vanessa Pedron OLTRAMARI-NAVARRO', \\ Ana Cláudia de Castro Ferreira CONTI', Ricardo de Lima NAVARRO' ${ }^{1}$, José Gustavo Dala Déa CAMACHO ${ }^{3}$

\begin{abstract}
1- DDS, MSc, PhD, Assistant Professor, Department of Orthodontics, University of North Paraná - UNOPAR, Londrina, PR, Brazil.
2- DDS, MSc, PhD, Assistant Professor, Department of Orthodontics, University of North Paraná - UNOPAR, Londrina, PR, Brazil; Associate Professor, Department of Pediatric Dentistry, Orthodontics and Community Health, Bauru School of Dentistry, University of São Paulo, Bauru, SP, Brazil.

3- DDS, MSc, Department of Orthodontics, University of North Paraná - UNOPAR, Londrina, PR, Brazil.
\end{abstract}

Corresponding address: Paula Vanessa Pedron Oltramari-Navarro - Rua Paranaguá, 803 - Apto 92 - 86020-030 - Londrina - PR - Phone: 43 9134-4499 e-mail: pvoltramari@hotmail.com

Received: April 05, 2010 - Modification: May 30, 2010 - Accepted: October 26, 2010

\section{ABSTRACT}

Angle Class III malocclusion has been a challenge for researchers concerning diagnosis, prognosis and treatment. It has a prevalence of $5 \%$ in the Brazilian population, and may have a genetic or environmental etiology. This malocclusion can be classified as dentoalveolar, skeletal or functional, which will determine the prognosis. Considering these topics, the aim of this study was to describe and discuss a clinical case with functional Class III malocclusion treated by a two-stage approach (interceptive and corrective), with a long-term follow-up. In this case, the patient was treated with a chincup and an Eschler arch, used simultaneously during 14 months, followed by corrective orthodontics. It should be noticed that, in this case, initial diagnosis at the centric relation allowed visualizing the anterior teeth in an edge-to-edge relationship, thereby favoring the prognosis. After completion of the treatment, the patient was followed for a 10-year period, and stability was observed. The clinical treatment results showed that it is possible to achieve favorable outcomes with early management in functional Class III malocclusion patients.

Key words: Interceptive orthodontics. Orthopedics. Angle Class III malocclusion. Stability.

\section{INTRODUCTION}

Angle Class III malocclusion has raised controversies among researchers concerning diagnosis, prognosis, and treatment. It affects $5 \%$ of the Brazilian population, with a greater incidence in people of Asian origin ${ }^{18}$.

In terms of etiology, this problem can have either a genetic origin ${ }^{21}$, with a more unfavorable prognosis ${ }^{1}$, or an environmental origin caused by more anterior and inferior tongue positioning ${ }^{3}$, habits, and oral breathing ${ }^{2}$.

Class III malocclusion can be classified as dentoalveolar, skeletal, or functional ${ }^{3}$, which will determine the diagnosis and prognosis. Ideally, diagnosis of this malocclusion should be made as early as possible, still during deciduous dentition. Early recognition of this discrepancy depends on a careful observation of a sequence of facial, occlusal, and cephalometric characteristics ${ }^{19}$. It is known that Class III malocclusion exacerbates during growth, mainly starting at adolescence. Therefore, in children, this malocclusion is not totally defined, and the not yet established facial and occlusal features can complicate the diagnosis ${ }^{11}$. The earlier the interceptive phase is initiated, the greater the orthopedic effects will be to the detriment of the unavoidable orthodontic effects ${ }^{9}$. Moreover, an early benefit in terms of esthetics for the child implies improved selfesteem, considering the psychological factor ${ }^{15}$.

Among the approaches for treating Class III malocclusion is the use of orthopedic appliances, such as chincups, facial masks, functional orthopedic appliances of the jaws, preventive orthodontic appliances (e.g.: Eschler arch and Porter appliance or " $W$ " arch), multibracket fixed appliances ${ }^{4,7}$, and a combined orthodontic and orthognatic surgery protocol ${ }^{8}$.

The correct indication of orthodontic therapy 
with a chincup depends on a precise diagnosis of Class III malocclusion ${ }^{20}$. It is advisable to initiate the treatment at an early age ${ }^{16,24}$, using an upward and backward ${ }^{16}$ force from $350 \mathrm{~g}$ to $500 \mathrm{~g}^{5,14,16,24}$. A cephalometric study performed by Graber $^{5}$ (1977) showed that the use of a chincup promoted a backward movement of Point $B$, due to a clockwise rotation of the mandible. The length of the mandible also decreased about $1 \mathrm{~mm}$ due to the pressure transmitted by the chincup to the condyle, which generated, on the other hand, a delay in vertical growth. In another study, Sakamoto, et al. ${ }^{17}$ (1984) evaluated the skeletal changes produced before, during and after chincup therapy. The authors concluded that chincup therapy would be a very useful and efficient method for correcting Class III with mandibular prognathism. Additionally, Sugawara, et al. ${ }^{20}$ (1990) verified that an early treatment with a chincup produced positive orthopedic effects on the mandible; however, they did not assure an improvement in the skeletal profile.

Another possibility of early interception in Class III treatment consists of an orthopedic/ orthodontic appliance, the so-called Eschler arch. This appliance has a modified labial bow, which will gently touch the lower incisor labial surface, and an acrylic occlusal bite-raising appliance, which affords normal growth of the maxilla, and helps the correction of the negative overjet ${ }^{6}$. Should it be necessary to correct the upper incisor inclination, finger springs can be used for their protrusion.

Considering the aforementioned therapeutic
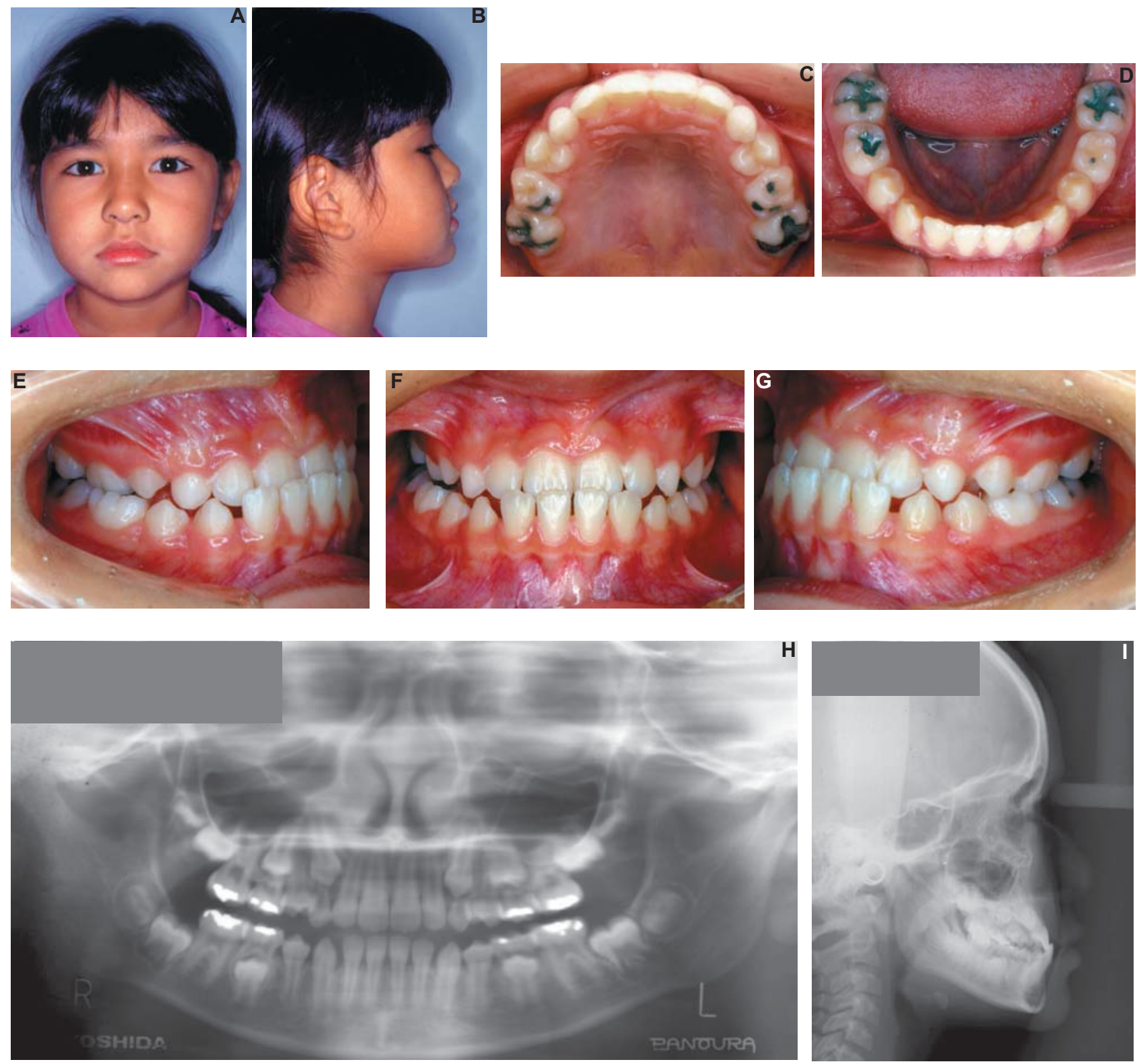

Figure 1-Pretreatment extraoral (A and B) and intraoral (C-G) photographs. Initial panoramic X-ray (H) and lateral cephalogram (I) (parents signed informed consent authorizing the publication of these pictures) 

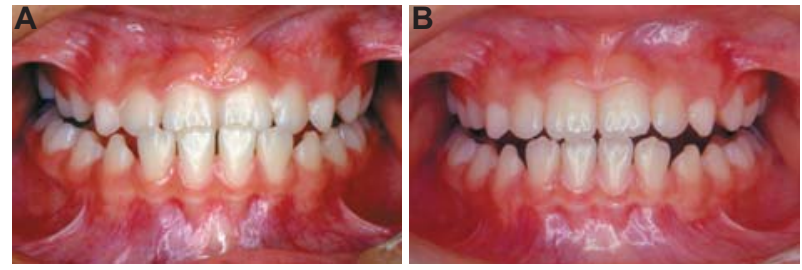

Figure 2- Frontal intraoral view showing an anterior crossbite - intercuspal position (A). Frontal intraoral view showing the edge-to-edge contact of the incisors - centric relation $(B)$
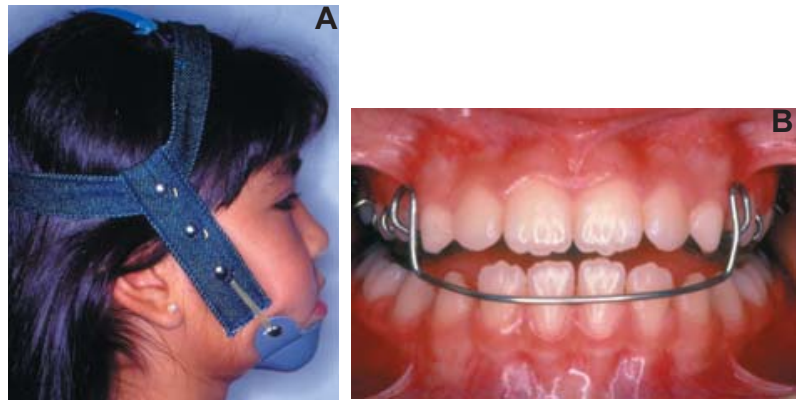

Figure 3- Extraoral (A) and intraoral (B) photographs (parents signed informed consent authorizing the publication of this picture)
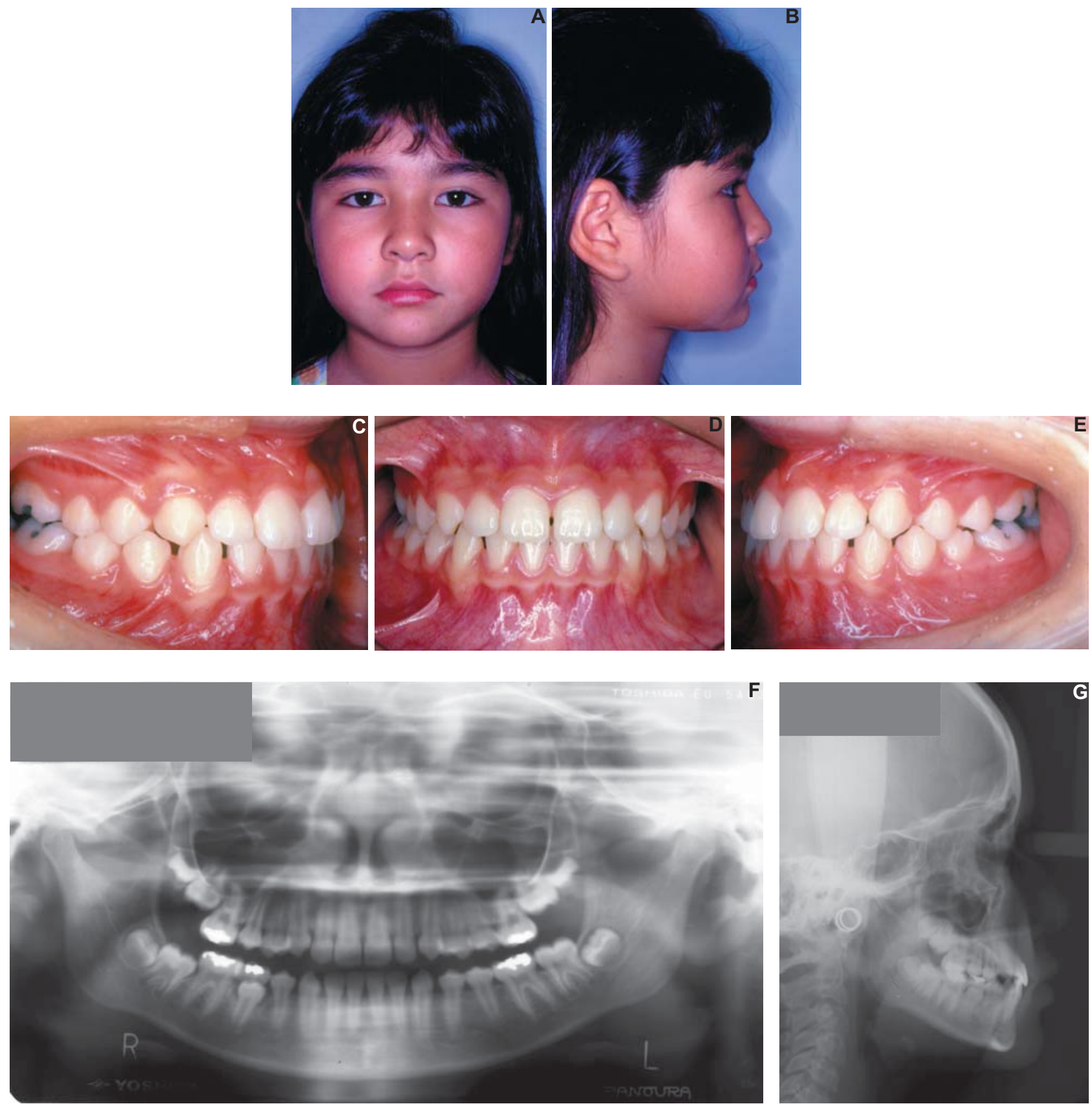

Figure 4- End of interceptive phase: extraoral $(A$ and $B)$ and intraoral $(C-E)$ photographs at the end of the interceptive phase, panoramic x-ray $(F)$ and lateral cephalogram $(G)$ (parents signed informed consent authorizing the publication of these pictures) 
possibilities, the aim of this study was to describe and discuss the treatment of a patient with Angle Class III malocclusion, treated according to a twostage approach (interceptive and corrective), and a long-term follow-up period.

\section{CASE REPORT}

A 9-year-old female patient in the mixed dentition stage (second transitional period) ${ }^{23}$ was referred for treatment with a chief complaint of an anterior crossbite. During the clinical interview, the presence of this malocclusion in other family members was reported. Facial evaluation showed lack of development of the middle third, which is an apparently normal feature for Asians. Intraoral examination revealed a forward shift of the mandible, with a marked mesial molar relationship, and a crossbite of the four permanent incisors, thus characterizing a functional Class III malocclusion (Figure 1).

A panoramic radiograph revealed the presence of all permanent teeth either erupted or in several developing stages. Careful evaluation of lateral cephalograms confirmed a Class III malocclusion, with an acute nasolabial angle, and a horizontal
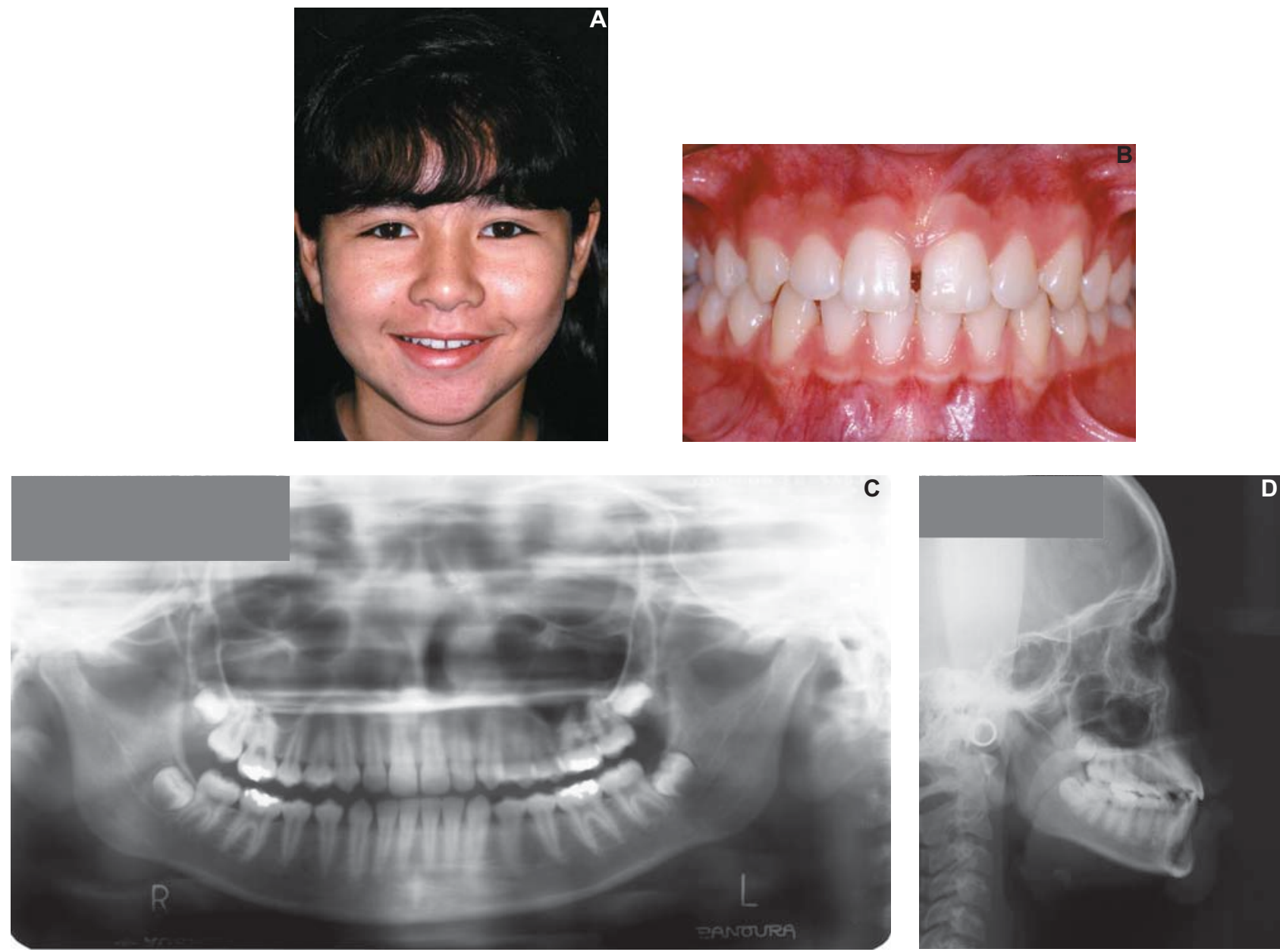

Figure 5- Two-year follow up after interceptive phase: extraoral $(A)$ and intraoral $(B)$ photographs presenting the diastema between upper central incisors. Lateral cephalogram $(C)$ and panoramic x-ray (D) (parents signed informed consent authorizing the publication of this picture)
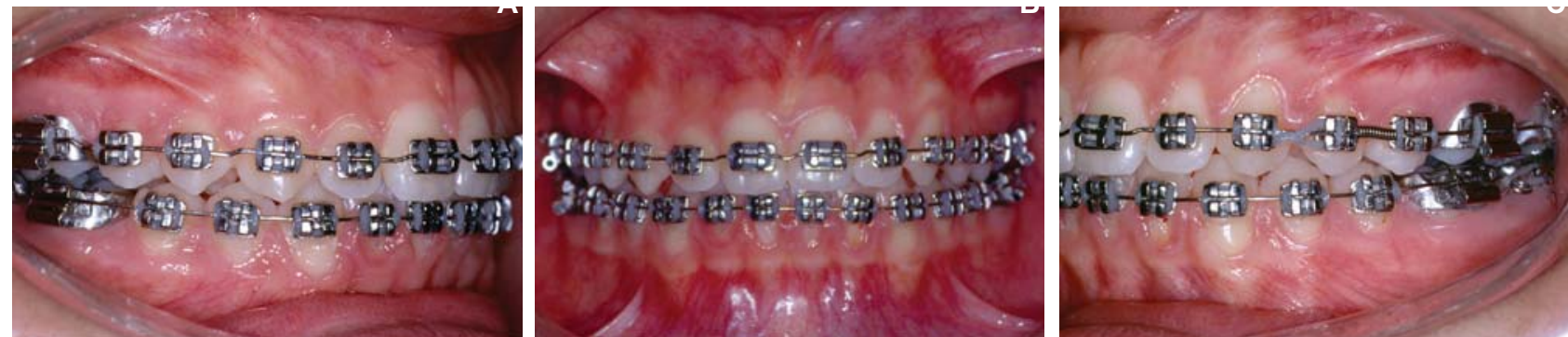

Figure 6- Intraoral photographs showing the fixed appliances $(A-C)$ 
growth pattern.

Following the confirmation of a Class III malocclusion through the cephalometric analysis, clinical differential diagnosis was accomplished by verifying the occlusion pattern at either the intercuspal position (IP) or at the centric relation (CR). The patient showed a crossbite at maximal habitual intercuspation with a forward shift of the mandible and, at $C R$, a retroposition of the mandible with edge-to-edge contact between the upper and lower incisors. This clinical condition confirmed a functional Class III malocclusion, which greatly favors the orthodontic treatment ${ }^{13}$ (Figure 2).

The patient was at a mixed dentition stage, with great potential of growth, so the main goal of the treatment was to correct the anterior crossbite, while also correcting the functional forward deviation of the mandible, and allowing the maxilla to be in a forward position in relation to the mandible, thus affording a normal development.

The proposed treatment protocol comprised two stages: the interceptive and the corrective
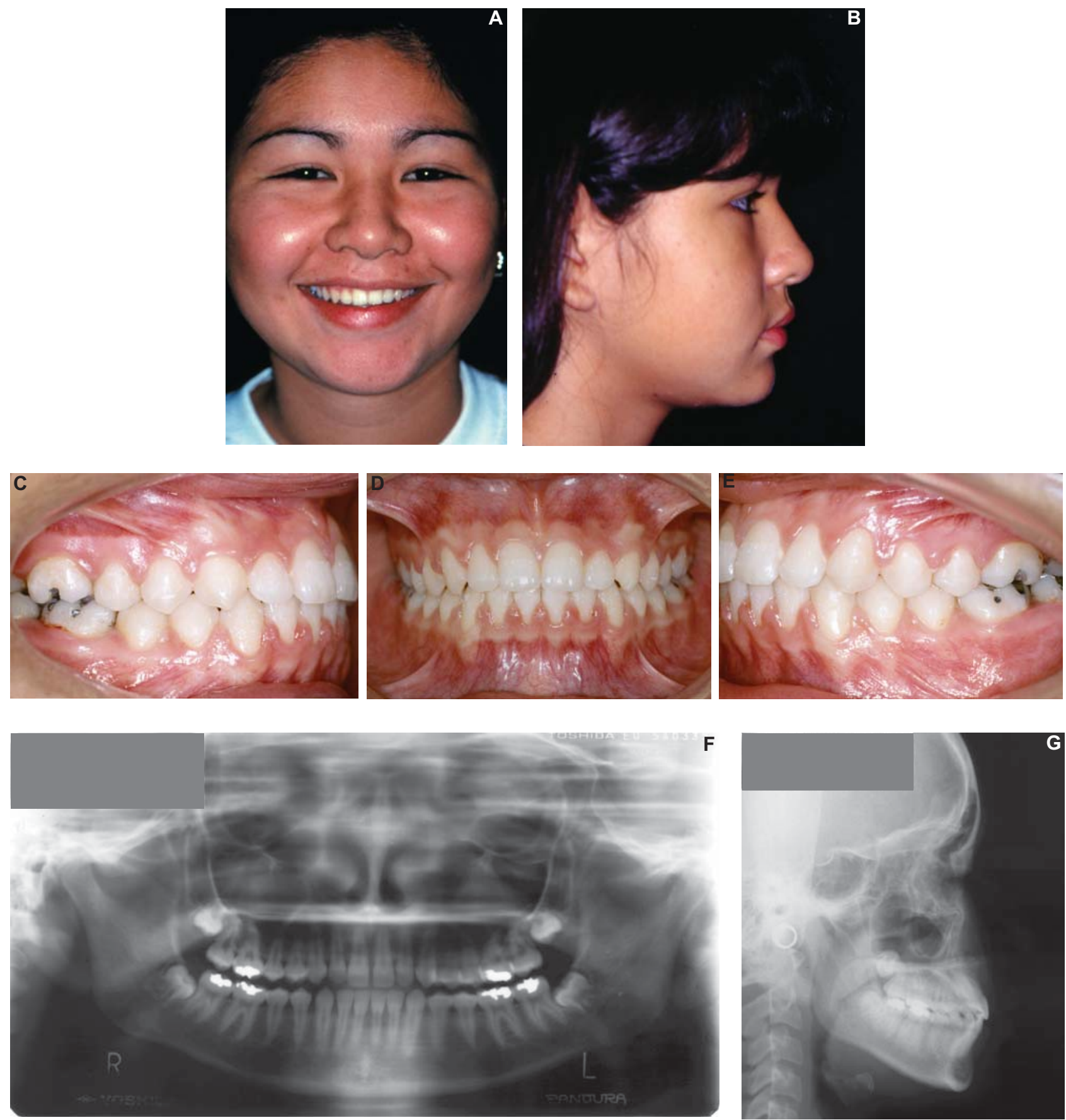

Figure 7- End of corrective phase: extraoral $(A, B)$ and intraoral $(C-E)$ photographs, Panoramic x-ray $(F)$ and Lateral cephalogram (G) (parents signed informed consent authorizing the publication of these pictures) 
phases. In the first phase, a chincup was used only at night to maintain mandibular retrusion, and the Eschler appliance, also known as "progenic appliance", was used during the day. The Eschler appliance is composed of: a) retention clasps, e.g. Adams clasps for molars, and intermolar auxiliary clasps for deciduous teeth and premolars, b) an Eschler labial bow, made in $0.9-\mathrm{mm}$ wire, and adapted at the labial surface of the lower incisors, c) an occlusal bite-raising appliance in acrylic resin with a thickness of 2 to $3 \mathrm{~mm}$. If necessary, springs and an expansor screw can be added (Figure 3 ).

The chincup was activated by $1 / 2$ inch elastics. These were changed either weekly or whenever necessary, and produced a force of $350 \mathrm{~g}$ to
$500 \mathrm{~g}$ on each side, directed at an angle of $45^{\circ}$ in relation to the occlusal plane ${ }^{22}$. A protocol of night-time wearing was recommended. Activation of the Eschler bow was performed by closing the loop sufficiently to make the bow touch the labial surface of the lower incisors, without overpressure, since the $0.9-\mathrm{mm}$ wire exerts intensified force due to its diameter. This appliance was intended to produce an orthopedic forward movement of the maxilla, and an orthodontic lingual movement of the lower incisors. After correcting the crossbite, the resin covering the occlusal surface was cut at each appointment. This was accomplished in order to allow the eruption of the premolars, eliminate the free space caused by the occlusal opening, and avoid a tongue interposition, and a possible
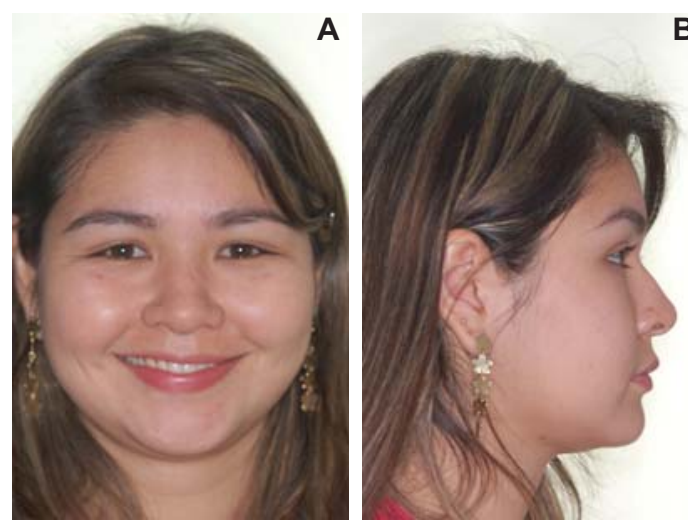

B
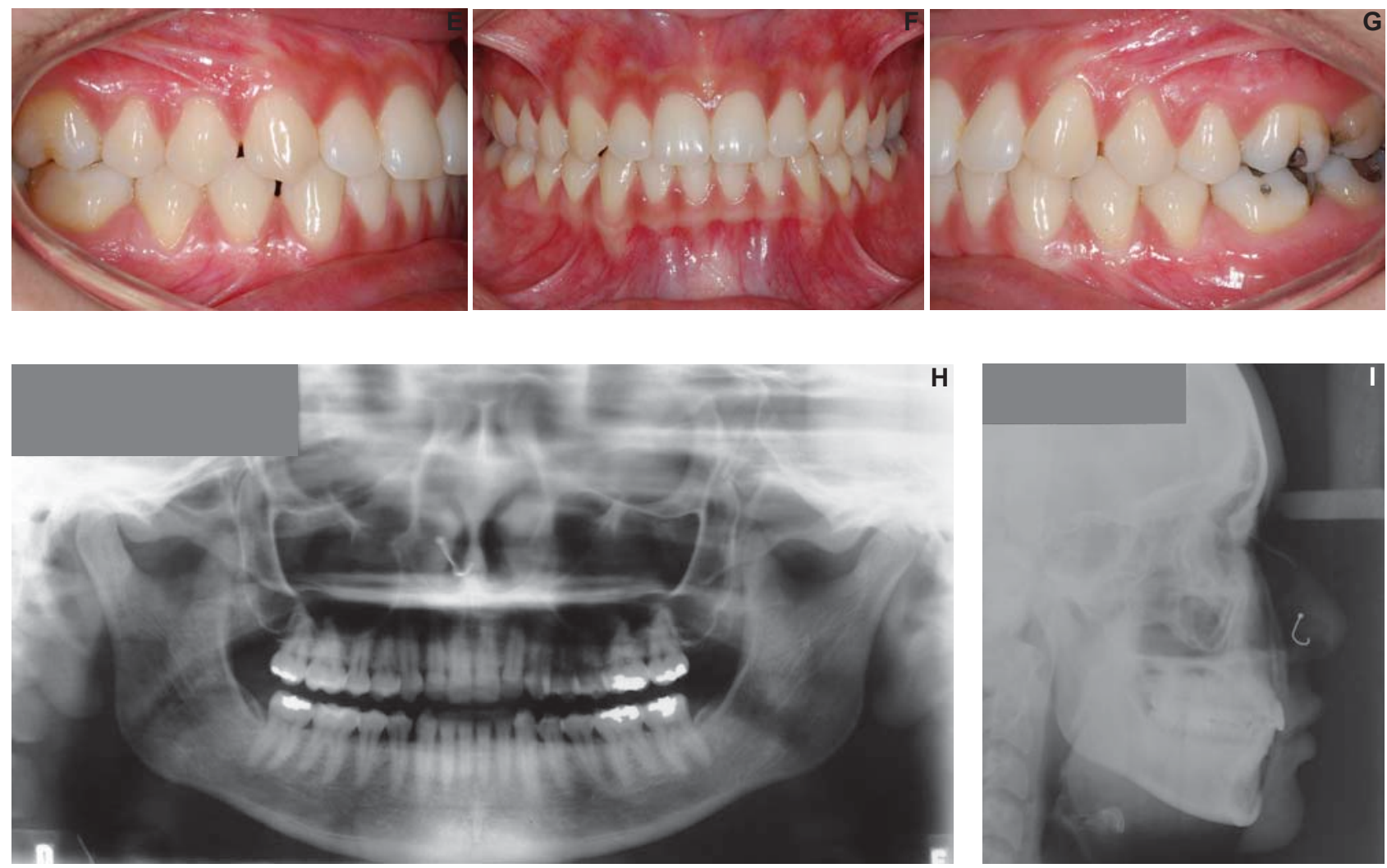

Figure 8- Follow-up at 10 years after the treatment: extraoral $(A$ and $B)$ and intraoral $(C-G)$ photographs, Panoramic $x$-ray $(\mathrm{H})$ and Lateral cephalogram (I) (patient signed informed consent authorizing the publication of these pictures) 
posterior open bite.

Follow-up appointments were scheduled until the complete correction of the anterior crossbite, totalizing a treatment period of 14 months. When the appliances were removed, the patient was seen every six months, up to the complete development of the permanent dentition, characterizing thus the end of the interceptive phase. In this phase, a
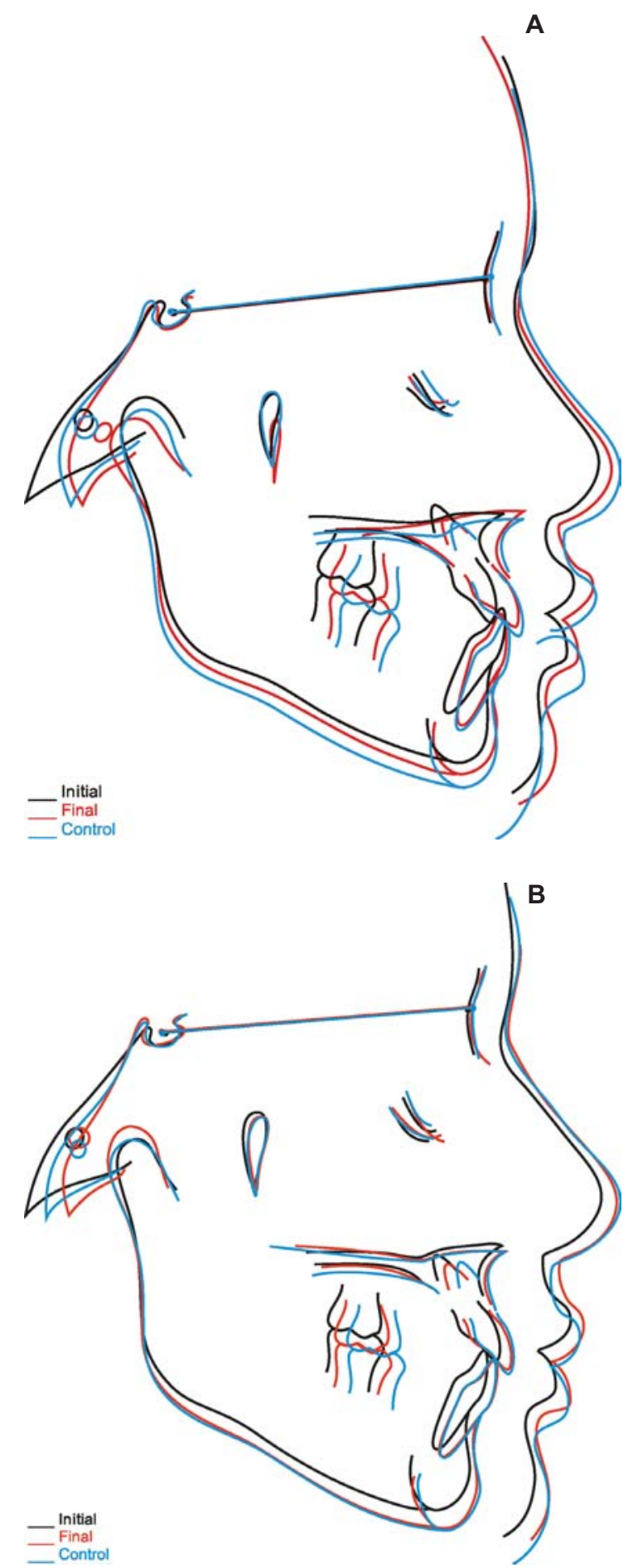

Figure 9- Superposition of initial, final, and followup cephalometric tracings of interceptive phase (A). Superposition of initial, final, and follow-up cephalometric tracings of corrective phase $(B)$ marked improvement in both facial harmony and occlusion was observed (Figure 4).

Lateral cephalograms (Figure 4) of the end of the interceptive phase showed the successful results of an early treatment with an Eschler appliance associated with a chincup. A panoramic radiograph showed the end of the mixed dentition, a good root parallelism, and the presence of the third molars (Figure 4).

During the development of the occlusion, the patient was concerned about the gradual increase of the diastema between the central incisors. However, this condition was expected, since the growing mandible caused the proclination of the incisors, thereby increasing arch length (Figure 5).

Approximately 2 years after the interceptive phase, and due to the patient's dissatisfaction with the diastema, the second phase of this protocol was initiated with the installation of a fixed appliance (Figure 6). The corrective phase aimed to close the diastema and perform small corrections, i.e., axial inclinations. It lasted for about 14 months and the results are shown in Figure 7.

Ten years after the corrective treatment, a new follow-up appointment verified stability of the treatment, and the final result can be seen in Figure 8. Figure 9 shows total superposition of the cephalometric tracings.

\section{DISCUSSION}

In this case, Class III was intercepted, and a fixed appliance was installed only to correct small rotations, the anterior diastema, and to improve axial teeth relationships. After the cephalometric analysis (Table 1), it was verified that the SNA angle continued to increase, while the SNB angle and Co-Gn were unaltered during the interceptive phase. This suggests that the treatment using chincup therapy was effective. The measurements representing the vertical position of the mandible, FMA, and SN.GoGn, were stable. The changes in linear and angular measurements of the upper and lower incisors contributed to obtain a positive overjet. From 9 to 12 years of age a proclination of the upper incisors from $20^{\circ}$ to $25^{\circ}$, and a retroclination of the lower incisors from $30^{\circ}$ to $22^{\circ}$ were observed. This possibly occurred due to the positive effect of the anterior crossbite correction.

Corrective orthodontic treatment was initiated 2 years after the finalization of the interceptive phase. Table 1 shows the cephalometric values at the initial, final, and 10-year post-corrective follow-up. It was observed that the ANB angle remained positive due to the stability of both SNA and SNB angles, as well as those for FMA and SN.GoGn. Conversely, CO-Gn showed an increase 
Table 1- Initial, final, and post-interceptive control cephalometric values

\begin{tabular}{|c|c|c|c|c|c|c|}
\hline $\begin{array}{l}\text { CEPHALOMETRIC } \\
\text { VARIABLES }\end{array}$ & $\begin{array}{l}\text { Interceptive } \\
\text { (initial) } \\
(9 \mathrm{y} 6 \mathrm{~m})\end{array}$ & $\begin{array}{c}\text { Post- } \\
\text { interceptive } \\
(10 \mathrm{y} 9 \mathrm{~m})\end{array}$ & $\begin{array}{c}\text { Interceptive } \\
\text { control } \\
(12 \mathrm{y} 4 \mathrm{~m})\end{array}$ & $\begin{array}{l}\text { Initial corrective } \\
\text { phase }(14 \mathrm{y} 2 \mathrm{~m})\end{array}$ & $\begin{array}{c}\text { Final } \\
\text { corrective } \\
\text { phase }(16 y 5 \mathrm{~m})\end{array}$ & $\begin{array}{l}\text { 10-year } \\
\text { follow- } \\
\text { up(26y8m) }\end{array}$ \\
\hline $\operatorname{SNA}\left({ }^{\circ}\right)$ & 84.5 & 86.0 & 87.0 & 89.0 & 90.0 & 90.0 \\
\hline SNB $\left(^{\circ}\right)$ & 85.0 & 84.0 & 84.5 & 86.0 & 87.0 & 87.0 \\
\hline ANB $\left({ }^{\circ}\right)$ & -0.5 & 2.0 & 2.5 & 3.0 & 3.0 & 3.0 \\
\hline $\operatorname{FMA}\left({ }^{\circ}\right)$ & 25.5 & 25.5 & 25.0 & 25.0 & 25.5 & 27.0 \\
\hline SN.GoGn $\left({ }^{\circ}\right)$ & 28.0 & 30.5 & 29.0 & 27.5 & 27.5 & 27.0 \\
\hline 1.NA $\left({ }^{\circ}\right)$ & 20.5 & 25.5 & 25.0 & 27.5 & 26.5 & 25.0 \\
\hline 1-NA (mm) & 2.0 & 3.5 & 3.5 & 4.0 & 5.0 & 5.0 \\
\hline 1.NB $\left({ }^{\circ}\right)$ & 30.0 & 21.5 & 22.0 & 27.0 & 28.0 & 28.5 \\
\hline 1-NB (mm) & 4.0 & 3.0 & 3.5 & 5.0 & 5.5 & 5.5 \\
\hline $\operatorname{IMPA}\left({ }^{\circ}\right)$ & 92.0 & 86.0 & 87.0 & 90.5 & 91.0 & 93.0 \\
\hline Co-A (mm) & 80.0 & 81.0 & 83.0 & 85.5 & 89.0 & 88.5 \\
\hline Co-Gn (mm) & 102.0 & 102.0 & 105.0 & 109.0 & 115.0 & 114.5 \\
\hline $\operatorname{NLA}\left({ }^{\circ}\right)$ & 103.0 & 104.0 & 106.0 & 90.0 & 92.0 & 93.0 \\
\hline Wits (mm) & -6.5 & -4.0 & -2.5 & -2.0 & -1.0 & -1.5 .0 \\
\hline
\end{tabular}

of $13 \mathrm{~mm}$, from the end of the interceptive phase to the 10-year follow-up after the corrective phase, showing a value similar to normal mandibular growth ${ }^{12}$. The measurements related to incisor inclinations remained stable at the 10year follow-up, contributing for the maintenance of the positive overjet.

The cephalometric analysis of the case under study demonstrated an increase of the ANB angle, mandible growth, and mandibular plane stability. The ANB was altered to a favorable value in the relationship of the jaws due to the treatment. The linear and angular measurement changes of upper and lower incisors helped to obtain a positive overjet. Sakamoto, et al. ${ }^{17}$ (1984), in a longitudinal study with skeletal Class III patients, radiographically evaluated the skeletal changes before, during and after chincup therapy. These authors demonstrated that the favorable outcomes obtained were limited to the corrective phase, but returned to the initial features, at the post-treatment period. This demonstrates that the prognosis of cases with great skeletal involvement would not be favorable, unlike the cases described in this report.

According to previous studies ${ }^{10,12}$, there should be proportional values between $\mathrm{Co}-\mathrm{A}$ and Co-Gn. This case initially demonstrated a Co-A measurement of $80 \mathrm{~mm}$, which should be $83 \mathrm{~mm}$, suggesting a maxillary deficiency. However, at the last follow-up appointment, this measurement was $88.5 \mathrm{~mm}$, which has been considered appropriate for a Co-Gn of $114.5 \mathrm{~mm}$.

This study demonstrated the achievement of optimal results, and the stability of the correction of a functional Class III malocclusion treated with a progenic appliance associated with a chincup, and followed by corrective orthodontics. In spite of the good outcomes achieved in this case, further long-term clinical investigations are necessary to assure the stability of Class III treatment.

\section{CONCLUSION}

This case report shows that that the stability of the correction of a functional Class III malocclusion with minor skeletal involvement is related to both the correct diagnosis and the early intervention. This treatment allowed proper facial growth and development, preventing worsening of the malocclusion, with more severe consequences.

\section{REFERENCES}

1- Arun T, Nalbantgil D, Sayinsu K. Orthodontic treatment protocol of Ehlers-Danlos syndrome type VI. Angle Orthod. 2006;76(1):177-83.

2- Chung JC. Redirecting the growth pattern with rapid maxillary expander and chin cup treatment: changing breathing pattern from oral to nasal. World J Orthod. 2006;7(3):236-53.

3- Cozzani G. Extraoral traction and class III treatment. Am J Orthod. $1981 ; 80(6): 638-50$.

4- Godt A, Zeyher C, Schatz-Maier D, Göz G. Early treatment to correct Class III relations with or without face masks. Angle Orthod. 2008;78(1):44-9.

5 - Graber LW. Chin cup therapy for mandibular prognathism. Am J Orthod. 1977;72(1):23-41.

6- Graber TM, Neumann B. Removable orthodontic appliances. $2^{\text {nd }}$ ed. Philadelphia: Saunders Co; 1984.

7- Janson G, Souza JEP, Barros SEC, Andrade P Jr, Nakamura AY. Orthodontic treatment alternative to a Class III subdivision malocclusion. J Appl Oral Sci. 2009;17(4):354-63. 
8- Janson M, Janson G, Sant'Ana E, Nakamura A, Freitas MR. Segmental LeFort I osteotomy for treatment of a Class III malocclusion with temporomandibular disorder. J Appl Oral Sci. 2008;16(4):302-9.

9- Kapust AJ, Sinclair PM, Turley PK. Cephalometric effects of face mask/expansion therapy in Class III children: a comparison of three age groups. Am J Orthod Dentofacial Orthop. $1998 ; 113(2): 204-12$

10- McNamara JA Jr. A method of cephalometric evaluation. Am J Orthod. 1984;86(6):449-69.

11- Oltramari PVP, Garib DG, Conti ACCF, Henriques JFC, Freitas MR. Orthopedical treatment of Class III in different facial patterns. R Dental Press Ortodon Ortop Facial. 2005;10(5):72-82.

12- Pinzan A, Pinzan-Vercelino CRM, Martins DR, Janson G, Henriques JFC, Freitas MR, et al. Atlas of craniofacial growth. $1^{\text {st }}$ ed. São Paulo: Santos; 2006.

13- Rabie AB, Gu Y. Diagnostic criteria for pseudo-Class III malocclusion. Am J Orthod Dentofacial Orthop. 2000;117(1):1-9. 14- Ritucci R, Nanda R. The effect of chin cup therapy on the growth and development of the cranial base and midface. Am J Orthod Dentofacial Orthop. 1986;90(6):475-83.

15- Saadia M, Torres E. Sagittal changes after maxillary protraction with expansion in Class III patients in the primary, mixed and late mixed dentitions: a longitudinal retrospective study. Am J Orthod Dentofacial Orthop. 2000;117(6):669-80.
16- Sakamoto T. Effective timing for application of orthopedic force in skeletal Class III malocclusion. Am J Orthod. 1981;80(4):411-6. 17- Sakamoto T, Iwase I, Uka A, Nakamura S. A roentgenocephalometric study of skeletal changes during and after chin cup treatment. Am J Orthod. 1984;85(4):341-50.

18- Silva Filho OG, Freitas SF, Cavassan AO. Prevalence of normal occlusion and malocclusion in Bauru (São Paulo) students. 1. Sagittal relation. Rev Odontol Univ Sao Paulo. 1990;4(2):130-7. 19- Silva Filho OG, Magro AC, Capelozza Filho L. Early treatment of the Class III malocclusion with rapid maxillary expansion and maxillary protraction. Am J Orthod Dentofacial Orthop. 1998;113(2):196-203.

20- Sugawara J, Asano T, Endo N, Mitani H. Long-term effects of chincup therapy on skeletal profile in mandibular prognathism. Am J Orthod Dentofacial Orthop. 1990;98(2):127-33.

21- Toffol LD, Pavoni C, Baccetti T, Franchi L, Cozza P. Orthopedic treatment outcomes in Class III malocclusion. A systematic review. Angle Orthod. 2008;78(3):561-73.

22- Vadiakas G, Viazis AD. Anterior crossbite correction in the early deciduous dentition. Am J Orthod Dentofacial Orthop. 1992;102(2):160-2.

23- Van Der Linden FPGM. Facial growth and facial orthopedics. $2^{\text {nd }}$ ed. Chicago: Quintessence; 1986.

24- Wendell PD, Nanda R, Sakamoto T, Nakamura S. The effects of chin cup therapy on the mandible: a longitudinal study. Am J Orthod Dentofacial Orthop. 1985;87(4):265-74. 